NOTICE: this is the author's version of a work that was accepted for publication in Hydrometallurgy. Changes resulting from the publishing process, such as peer review, editing, corrections, structural formatting, and other quality control mechanisms may not be reflected in this document. Changes may have been made to this work since it was submitted for publication. A definitive version was subsequently published in Hydrometallurgy, Volume 137, May 2013, Pages 84-91. http://doi.org/10.1016/j.hydromet.2013.05.006 


\section{Crystallization of sodalite particles under Bayer-type conditions}

Tomoko Radomirovic^, Peter Smith ${ }^{\#}$, Daniel Southam^, Sonam Tashi^, Franca Jones^**

*corresponding author

AJ Parker CRC for Integrated Hydrometallurgy Solutions,

NDepartment of Chemistry, Curtin University GPO Box U1987 Perth WA 6845

${ }^{*}$ CSIRO Process Science and Engineering, Waterford WA

\subsection{Abstract}

The formation of desilication products (DSPs) is an important process in the pre-desilication step of the Bayer process, helping to limit the potential for unwanted scale on the heat exchangers by limiting the amount of silicate in the Bayer liquor. These solids generally have a crystalline sodalite structure, however, the fundamentals of crystallization are still to be fully understood. We show in this work that the DSP formed is initially amorphous when solution silicate is used. When kaolinite solids are present DSP is initially heterogeneously nucleated on the kaolinite but there is also a secondary nucleation event that occurs.

Keywords: Bayer process, DSP, silicate, secondary nucleation, heterogenous nucleation, kaolin

\subsection{Introduction}

The Bayer process is the most commonly used method of refining bauxite to alumina worldwide. It is an essentially simple method whereby aluminium bearing minerals are dissolved in concentrated caustic and once the gangue is removed, gibbsite is precipitated before being calcined to alumina (1). The simplicity is somewhat deceptive as other species are known to dissolve into the caustic at differing degrees causing unwanted side-effects (2, 3). One important class of species, that this paper focuses on, is that of silicates. While very crystalline silicates such as quartz can go through the low temperature $\left(\sim 150{ }^{\circ} \mathrm{C}\right)$ Bayer 
process almost untouched, many aluminosilicate clays are actually soluble $(4,5)$. For this reason, the Bayer industry normally refers to 'reactive silicas', which in essence is a pseudonym for 'Bayer liquor soluble silicates'.

Desilication products (DSPs) form in the Bayer process due to the dissolution of these soluble clays reacting with the aluminate from the Bayer liquor to form less soluble crystalline aluminosilicates $(6,7)$. These tend to be zeolite-like sodalite or cancrinite type structures with many different anions (from the Bayer liquor itself) trapped in the zeolitic cages $(6,7)$. The formation of DSPs in the Bayer process is both desirable and undesirable depending on where in the process it occurs. Excess silicate in solution can precipitate onto the heat exchangers as scale (after the crystallization of gibbsite) decreasing heat exchanger efficiency (8). To combat this, a pre-desilication step prior to the digestion phase is normally operated. In this part of the process the reactive silicas are dissolved and re-precipitated as DSPs thus lowering the dissolved silicate level in Bayer liquors (9). However, even this operation of forming DSPs has some disadvantages not least of which is the loss of soda due to entrapment into the sodalite cages (5).

Previous work in this area found that the formation of DSP is thought to be in the sequence shown below (10).

Aluminosilicate species $\rightarrow$ Amorphous phase $\rightarrow$ Zeolite A $\rightarrow$ Sodalite $\rightarrow$ Cancrinite while Bayer impurities tend to change the species observed (11). However, these studies are in unseeded systems, using soluble silicate sources and so do not directly relate to the Bayer process. In addition, while the structures of the solids are known, the mechanisms by which they form (homogenous versus heterogenous nucleation etc.) are unknown. Previous literature even suggested a possible solid-state transformation (12). 
This work attempts to understand the process of DSP formation at a fundamental level. What are the mechanisms of nucleation and growth of DSP from both liquid and solid silicate sources? How does the formation of DSP from kaolinite proceed?

\subsection{Experimental}

All the materials and methods other than the AFM method has been previously discussed in (13) and will only be briefly covered here.

\subsection{Materials}

Sodium hydroxide, sodium carbonate and sodium sulfate (AR grade, Aldrich) were used to make the synthetic liquor. This involved initially dissolving the sodium hydroxide into water and subsequently adding gibbsite (C33, Alcoa of Arkansas, Pty. Ltd.). The slurry was heated to dissolve all the solids. Sodium carbonate $(30 \mathrm{~g} / \mathrm{L})$ and sodium sulfate $(10 \mathrm{~g} / \mathrm{L})$ were dissolved in water separately and once the gibbsite was dissolved the two solutions were mixed. The resultant solution was filtered and allowed to cool prior to adjusting to the desired volume. Waterglass solution (PQ Corporation - D Grade) was found to be $29.4 \mathrm{wt} \% \mathrm{SiO}_{2}$, 14.7 wt $\% \mathrm{Na}_{2} \mathrm{O}, 55.9$ wt $\% \mathrm{H}_{2} \mathrm{O}$ and sodium metasilicate pentahydrate (AR grade, Aldrich) were used as received. The kaolinite used was a Snobrite 65 kaolinite from Unimin Corp. (Australia). It was characterised by SEM, DLS, and XRD $(13,14)$. The chemical composition (by XRF) of this kaolinite is given in (14). 


\subsection{Liquor Analysis}

The spent liquor was analysed using the method of Connop (15) and the following characteristics were determined. The following conventions are used along with the average values for the liquors (composition was not varied unless otherwise stated)

$\mathrm{C}=$ total caustic $\left(\mathrm{NaOH}+\mathrm{NaAl}(\mathrm{OH})_{4}\right)$ expressed as equivalent sodium carbonate $(\mathrm{g} / \mathrm{L}$ $\left.\mathrm{Na}_{2} \mathrm{CO}_{3}\right)=250 \pm 20$

$\mathrm{A}=\mathrm{Al}$ content expressed as equivalent alumina $\left(\mathrm{g} / \mathrm{L} \mathrm{Al}_{2} \mathrm{O}_{3}\right)=\mathbf{7 5} \pm \mathbf{1 3}$

$\mathrm{S}=$ caustic + carbonate content expressed as equivalent sodium carbonate $\left(\mathrm{g} / \mathrm{L} \mathrm{Na} \mathrm{NO}_{3}\right)=$ $280 \pm 20$

$\mathrm{A} / \mathrm{C}=$ ratio of $\mathrm{A}$ and $\mathrm{C}$ (gives an indication of the saturation state of the liquor) $=\mathbf{0 . 3} \pm \mathbf{0 . 0 5}$

An A/C value of 0.3 is indicative of a spent liquor in the plant situation.

In addition, as mentioned above, $10 \mathrm{~g} / \mathrm{L}$ sodium sulfate was also present in the liquor.

Pure caustic having a $\mathrm{C}=250$ with no carbonate, gibbsite or sulfate present was used for dilution purposes as well as a test liquor.

\subsection{UV-vis method}

The UV-vis method developed has been previously described (13), it essentially measures the absorbed light at a fixed wavelength where absorption of the slurry is expected to be negligible. In this way the UV instrument can be used as a turbidity meter (16).

\subsection{Monitoring of reactions}

Caustic or Bayer liquor (300 mL) was added to a stainless steel jacketed reactor and equilibrated to temperature using a water bath at either 80 or $90{ }^{\circ} \mathrm{C}$. A stainless steel stirring rod fitted to an overhead stirrer was used to mix the slurry at $400 \mathrm{rpm}$. A known quantity of 
silicate (soluble or solid source) was then added to the reactor and the reaction sampled at known time intervals. The sample was placed into a quartz cuvette and inverted prior to placing into the instrument to re-disperse any solids present. The maximum absorbance reading was taken (since settling of particles can occur over time). The solids collected at different time intervals were filtered through a caustic resistant $0.2 \mu \mathrm{m}$ membrane, washed thoroughly with water and dried in a desiccator. These dried solids were then analysed by XRD (Philips Xpert Instrument, Co $\mathrm{K}_{\alpha}$ ) and scanning electron microscopy (Zeiss Evo or Philips XL30 SEM instrument).

\subsection{Atomic Force Microscopy (AFM) studies}

$E x$-situ samples were prepared by taking the solids obtained from the reactor (for the UV-vis method) at different times and thoroughly washing them with water before drying them in a desiccator. They were then re-dispersed in water and spun coated onto flat mica pieces stuck with tape to an AFM stub. For the ex-situ work both the contact and tapping modes were utilised. All images were collected using a PicoPlus (Molecular Imaging) AFM and silicon nitride cantilever.

\subsection{Dynamic Light Scattering (DLS)}

A NanoZS (Malvern) was used to measure the particle number and size remaining in solution after removal of the larger kaolinite particles. The slurry was sampled during a kaolinite dissolution experiment at different times and the kaolinite particles removed by filtration through a $0.2 \mu \mathrm{m}$ caustic resistant membrane. Sonication (low powered- bath sonicator Soniclean 160HT from Soniclean Pty Ltd Australia; high powered sonication - horn sonicator UP400S from Heilscher Germany) was used to disperse any aggregates and then the solution measured for particle size and number immediately. 


\subsection{Results and Discussion}

\subsection{Soluble silicates}

\subsubsection{Waterglass solution at $80{ }^{\circ} \mathrm{C}$ in synthetic Bayer liquor}

The turbidity results (Fig. 1) show that when waterglass solution is added there is an initial increase in turbidity followed by a decrease in solution turbidity spanning approximately 50 minutes. After this, depending on the silicate concentration, a second increase in the turbidity is observed for $\mathrm{SiO} 2$ levels $\geq \sim 2 \mathrm{~g} / \mathrm{L}$. The magnitude of the increase and the 'induction' time prior to this second turbidity increase is dependant on the silicate concentration.

Figure 1 near here

It is clear that as the concentration of waterglass is increased, so too does the final size of the particles formed (Fig. 2). More importantly perhaps, the particles observed at low waterglass concentrations do not have the 'woolly ball' morphology. Also, note that the UV-Vis technique was not able to detect those particles formed at $<1.1 \mathrm{~g} / \mathrm{L} \mathrm{SiO}_{2}$ where particles were $\leq 400 \mathrm{~nm}$ diameter (this being the size limit for this method, ref 12). It is also interesting to note that at this addition of waterglass, the particles appear to be platelet-like (see supplementary information, Fig. S1) with twinning of platelets common. The formation of aluminosilicates as platelets evolving over time into spherical structures is not unheard of as discussed in ref 17.

Figure 2 near here 
$\mathrm{XRD}$ of the solids formed at the higher waterglass contents taken and filtered at 10 minutes showed that the original material precipitated (see supplementary information, Fig. S2) was an essentially amorphous solid having a main but very broad band at 2theta $=33^{\circ}$ (with a minor crystalline phase present, having 2theta reflections at $\sim 43,52$ and $78{ }^{\circ}$ ) while the final XRD pattern was consistent with sodalite (see supplementary information, Fig. S3).

The SEM of the solids at 10 minutes showed platelet-like and fluffy material. Thus, it can be confirmed that in the presence of waterglass the original precipitate is an amorphous product that either re-dissolves or undergoes some transformation to a crystalline product as found by both Barnes et al. (10), and Armstrong (11). It should be noted that the crystalline reflections observed at 10 minutes are not discernible at 5 hours. Furthermore, these peaks cannot be associated with residual solids since a liquid silicate solution was used and no solids were present. Initial work by Lowe $(18,19)$, suggested that soluble silicates precipitate via a zeolite A phase, however, these reflections do not correspond to zeolite A and could be simply contaminant peaks. We would hypothesise that this result suggests that initially an amorphous silicate is formed. Over long periods (5 hours) we see this transform to the nosean sodalite structure as expected for sulfate containing liquors.

\subsubsection{Metasilicate solution in synthetic Bayer liquor}

The behaviour of metasilicate solution is similar to waterglass solution but slightly different. As can be seen (Fig. 3), no initial rise in turbidity is observed, unlike the waterglass solution experiments seen above. On the other hand, as found for waterglass, the induction time is proportional to the metasilicate solution added. From SEM images (supplementary information, Fig. S4), the solids eventually form the 'woolly ball' morphology but as per the waterglass solution, small particles $\leq 400 \mathrm{~nm}$ are initially formed at the lower concentrations. 
There is also less correlation between the final particle size and the supersaturation when metasilicate is used as the source of silicate.

Figure 3 near here

At $90{ }^{\circ} \mathrm{C}$, the metasilicate solution shows the same trends but the nucleation event is seen much sooner (Fig. 3b). Also, the limit to seeing the nucleation event drops to lower silicate concentrations $\left(\sim 1.1 \mathrm{~g} / \mathrm{L} \mathrm{SiO}_{2}\right)$ than at $80{ }^{\circ} \mathrm{C}$. The observance of a rise in turbidity at the same metasilicate concentration but different temperatures suggests either a slightly lower solubility or an increase in kinetics with the change in temperature. However, the solubility is not expected to be significantly lower at 90 compared to $80{ }^{\circ} \mathrm{C}$ according to ref 20 , thus we conclude that increased crystallization kinetics is indeed the culprit behind these observations. It is interesting to note that not only are the nosean 'woolly' ball particles smaller at the lower concentrations, but so too are the initial more amorphous looking particles (Fig. 4).

Figure 4 near here

In addition we can look at the crystallinity of the products using XRD. As found for waterglass, the initial precipitate formed when metasilicate solution is added is an amorphous product (see Fig. 5), the degree of amorphous character depending on the temperature. At $80^{\circ} \mathrm{C}$, the addition of metasilicate shows no crystalline peaks while a small increase in temperature results in some peaks being observed.

Figure 6 near here 
Thus, the kinetics of the amorphous to crystalline transformation appears to determine whether the amorphous phase is observed. Thus, for industrial situations at $\sim 150{ }^{\circ} \mathrm{C}$, any amorphous phase is expected to quickly transform to the crystalline phase.

We can conclude therefore, that the observation of a crystalline phase such as zeolite A (21) is either due to higher temperatures being investigated or long sampling times (meaning any amorphous structures have converted to crystalline) and that DSP formation begins with an amorphous solid if the silicate source is a dissolved one. This is further confirmed by the final product formed being the same as the final product for waterglass addition - nosean (see supplementary information, Fig. S5).

\subsection{Solid silicate sources - kaolinite}

The dissolution of kaolinite in Bayer liquors is dependent on the free caustic. The free caustic takes into consideration that 1 mole of caustic is required to dissolve 1 mole of gibbsite according to:

$$
\mathrm{Al}(\mathrm{OH})_{3}+\mathrm{NaOH} \rightarrow \mathrm{Na}^{+}+\mathrm{Al}(\mathrm{OH})_{4}^{-}
$$

Thus:

$$
\begin{aligned}
\text { Free Caustic } & =\mathrm{C}-\mathrm{OH} \text { required to form aluminate } \\
& =\mathrm{C}-\mathrm{A}^{*}(1.039)
\end{aligned}
$$

When the initial A/C (0.4) was kept constant but the initial free caustic strength was altered the results in Fig. 6a are obtained. When the initial A/C was allowed to change but the initial free caustic was held fixed the results in Fig. 6b were observed. Firstly, we can see that the increase in free caustic results in an increase in the rate of dissolution of kaolinite solids. 
Equilibrium arguments would only suggest that the amount of kaolinite that dissolves should be higher, however, these results indicate that the rate of dissolution is also impacted on slightly. In fact, the amount of kaolinite dissolved does not appear to be appreciably different, however, this could be because i) there is only a small difference in the initial free caustic (88 versus $119 \mathrm{~g} / \mathrm{L}$ ) and/or ii) the experiment was halted at 400 minutes.

\section{Figure 6 near here}

When the initial free caustic level is kept constant, the rate of kaolinite dissolution is also constant but now we see DSP crystallization occurring at an $\mathrm{A} / \mathrm{C}=0.2$ (increase in turbidity at 200 min) while no DSP formation occurs at the higher aluminate level. This confirms plant knowledge that DSP precipitates after the gibbsite precipitation stage thus at low A/Cs DSP precipitation results while at high $\mathrm{A} / \mathrm{Cs}$ aluminosilicate in solution is somewhat stabilised (22). We can also see that in pure caustic dissolution only is observed even when the solids concentration is equivalent to that in Bayer liquor (see Fig. 7). This is an interesting point, which in essence shows that the aluminate concentration may stabilise aluminosilicate in solutions at high aluminate concentrations but the absence of aluminate altogether leads to greater kaolinite dissolution (and therefore higher aluminosilicate levels in solution). Thus DSP solubility must have a minimum in low aluminate Bayer liquors. There are only a few papers discussing the solubility of DSP in caustic and Bayer liquor; Roach (23), Breuer (21) and Barrer et al., (24) being the most relevant. At a FC of 100 in pure caustic, DSP will dissolve to a level of $\sim 0.22 \mathrm{~g} / \mathrm{L} \mathrm{SiO}_{2}$ (24); while a Bayer liquor with the same FC would have a $\mathrm{C} 110$ and an $\mathrm{A} / \mathrm{C}=0.1$ and would result in DSP dissolution of less than $0.2 \mathrm{~g} / \mathrm{L} \mathrm{SiO}_{2}(21)$. The work of Breuer (21) clearly shows that as A/C increases so too does the DSP dissolution and this confirms our findings here that DSP has a minimum solubility in low A/C liquors. 
Figure 7 near here

The increase in turbidity at $90{ }^{\circ} \mathrm{C}$ in synthetic Bayer liquor is important. Firstly, it is dependant on the kaolinite solids present. The higher the kaolinite solids loading the sooner the upturn in turbidity is observed but the level of kaolinite dissolved is calculated to be similar in both cases (difference in absorbance from the initial reading to the turning point is 1.37 when $0.5 \mathrm{wt} \%$ kaolinite present and 1.27 when $0.33 \mathrm{wt} \%$ kaolinite present). Using the relationship between absorbance and solids derived in ref 13, gives the solids dissolved as 0.75 and 0.72 g respectively (equating to $0.03 \mathrm{wt} \%$ difference in the dissolution of the kaolinite for both solids contents). This would be expected given that the rate of dissolution may be increased as more kaolinite is present but the solubility limit for DSP would be fixed for each temperature (in a pure system). Secondly, we must determine the cause of the upturn in turbidity. A turbidity increase can happen via three mechanisms; i) the size of the particles is altering (increasing) or ii) the number of the particles is increasing or iii) both.

As seen in the SEM images in Fig. 8, some kaolinite particles sitting vertically contain DSP nuclei (at $\sim 150 \mathrm{~min}$ ) that could not have resulted from settling into that position. This suggests a primary heterogeneous nucleation event of the DSP on the kaolinite surface. In addition, high magnification SEM images suggest the DSP initially crystallizes 'perpendicularly' to the kaolinite (see supplementary information Fig. S6). More importantly, the change in size by the presence of these nuclei on the surface would not be expected to contribute significantly to the upturn in turbidity. Thus, from the increased DSP particles observable in the SEM images, we would surmise a secondary nucleation event has also occurred. We can, however, categorically state that DSP formation from kaolinite in synthetic 
Bayer liquor is not a homogenous nucleation event. During the 5 hours of the experiment, these DSP particles grow into roughly spherical particles of $500 \mathrm{~nm}$ in diameter and as they grow the kaolinite eventually dissolves releasing these nuclei into solution. This may involve an epitaxial match of the kaolinite substrate to the forming DSP structure since it is known that kaolinite has 'gibbsitic' layers and silicate rich layers, however, it may also be due to these sites having a high local aluminate and silicate concentration. Eventually, the kaolinite will dissolve completely and release the DSP particles into solution. Thus, while the initial process may be a heterogeneous nucleation event, overall this is a secondary nucleation mechanism (secondary nucleation is defined (25) as nucleation that occurs due to solute particles being present - in this case the heterogenous nucleation of DSP on kaolinite appears to promote the nucleation of new DSP particles). It is possible that in the early stages these heterogeneously nucleated nuclei are also amorphous in nature and are difficult to visualise.

Figure 8 near here

In addition, we can be confident that the kaolinite to DSP transformation is not a solid state transformation due to the obvious signs of kaolin dissolution in caustic (see supplementary information, Fig. S7).

An attempt was made to determine the nuclei size and number from dynamic light scattering (DLS) measurements using the same conditions $\left(90^{\circ} \mathrm{C}, 0.5 \mathrm{wt} \%\right.$ kaolin in Bayer liquor) as per the UV-vis method. The results showed that the particles filtered through $0.2 \mu$ m underwent aggregation despite the addition of hexametaphosphate (due to the presence of 'particles' larger than $200 \mathrm{~nm}$, data not shown). In terms of particle number, both low and high powered sonication (to disperse aggregates) gave the same trend. Interestingly, DLS results suggest 
that the nucleation of the small DSP particles has already occurred by 60 minutes (Fig. 9) as shown by the large particle counts at this time period. Their numbers steadily decrease over time as they grow and agglomerate. This is in contrast to the SEM data in Fig. 9 that suggests that the secondary nucleation event occurs at $~ 90-120$ minutes. The results from the soluble metasilicate addition (Fig. 3) show that addition of $\sim 0.3 \mathrm{~g} / \mathrm{L} \mathrm{SiO}_{2}$ has an induction time of roughly 30 minutes. At 20 minutes, $0.25 \mathrm{~g} / \mathrm{L} \mathrm{SiO}_{2}$ has dissolved from the kaolinite, thus if this had an induction time of $~ 30$ minutes then particles would begin to be observed at $~ 50-60$ minutes (20minutes for the dissolution to occur +30 minutes induction time). Thus, it is possible that the turbidimetric (UV-vis) method at 50-60 minutes is still measuring the kaolinite dissolution process because the initial stage is the heterogenous (surface) nucleation of the DSP particles on kaolinite particles. It is known from previous work (13) that the UVvis method requires particles of $\geq 400 \mathrm{~nm}$ for detection.

Figure 9 near here

\subsubsection{AFM studies}

The solids were imaged using the tapping mode capability as well as the contact mode. This allows both height and phase images to be obtained. The phase image is interesting in that it will be impacted by the physical properties of the solid, e.g. hardness. The Mohs hardness for mica is $2-3$, kaolin is $2-2.5$ and sodalite/nosean is 5-6 (26). Thus, differences in the phase image are expected based on hardness differences between kaolin and sodalite.

However, in these ex-situ experiments no discernible differences in hardness could be obtained for DSP particles and kaolinite (see Fig. 10). The possibility arises that the DSP and kaolinite particle surfaces have been altered on drying, in particular, a layer of material may 
cover the surface, rendering it impossible to determine hardness differences of the material underneath.

Figure 10 near here

\subsection{Summary}

In conclusion, we have shown that for the soluble sources of silicate in solution, the formation of DSP is initially through an amorphous phase. This amorphous phase can be observed up to least 10 minutes but is highly temperature dependant. As the temperature is increased the longevity of the amorphous phase is decreased. This suggests a kinetically controlled amorphous to crystalline transition.

The work presented here gives confirmation that high aluminate concentrations stabilise aluminosilicate in solution somewhat. However, the fact that silicate is also more soluble in pure caustic leads to the conclusion that there is a minimum aluminosilicate solubility at low aluminate concentrations.

SEM images clearly show that DSP is originally formed on the surface of the dissolving kaolinite, meaning that the first stage of DSP formation is a heterogenous nucleation stage. However, as more kaolinite dissolves these DSP nuclei are released into solution and more nuclei form, leading to an overall secondary nucleation mechanism.

Finally, AFM shows that the dissolution of the kaolinite and subsequent formation of DSP is not observable by measuring hardness changes (tapping mode) and therefore may involve the formation of an amorphous surface layer (making the surface softer than the DSP bulk). 


\subsection{Acknowledgements}

F. Jones and P. Smith gratefully acknowledge that this research has been supported under the Australian Government's Cooperative Research Centre (CRC) Program, through the AJ Parker CRC for Integrated Hydrometallurgy Solutions.

\subsection{References}

1. A. R. Hind, S. K. Bhargava, S. C. Grocott, (1999) “The surface chemistry of Bayer process solids: a review” Colloids and Surfaces A: Physicochemical and Engineering Aspects, 146, 359-374.

2. M. Authier-Martin, G. Forte, S. Ostap, J. See, (2001) “The mineralogy of bauxite for producing smelter-grade alumina” J. Miner., Dec, 36-40.

3. A. V. Ellis, M. A. Wilson, K. Kannangara (2002) "Bayer poisons: Degradation of angiosperm and gymnosperm water-soluble extracts in sodium hydroxide at $145^{\circ} \mathrm{C}^{\prime}$ Ind. Eng. Chem. Res., 41, 2842-2852

4. T. Oku, K. Yamada (1971) "Dissolution of quartz and the rate of desilication in the Bayer liquor” Light Metals, 31-45.

5. D. Croker, M. Loan, B. K. Hodnett (2008) “Desilication reactions at digestion conditions: An in situ X-ray diffraction study” Crystal Growth and Design, 8(12), 4499-4505.

6. Whittington, B. I., Fletcher, B. L. \& Talbot, C. (1998), “The effect of reaction conditions on the composition of desilication product (DSP) formed under simulated Bayer conditions” Hydrometallurgy, 49, 1-22.

7. B. Xu, P. Smith, C. Wingate, L. De Silva (2010), “The effect of calcium and temperature on the transformation of sodalite to cancrinite in Bayer digestion”, Hydrometallurgy, 105(12), 75-81. 
8. A. R. Gerson, J. Addai-Mensah, K. Zheng, A. O’Dea, R. Smart (1996), “The mechanism of sodium aluminosilicate scale formation in alumina refineries” Proceedings of the $4^{\text {th }}$ Alumina Quality Workshop, Darwin, Australia, 393-400.

9. P. Smith (2009) “The processing of high silica bauxites — Review of existing and potential processes” Hydrometallurgy, 98, 162-176.

10. M .C. Barnes, J. Addai-Mensah, A. R. Gerson, R. C. St. Smart (1999) “The solubility of $\mathrm{SiO}_{2}$ in synthetic spent Bayer liquor seeded with sodalite and cancrinite” J. Colloids and Surfaces A 157, 101-116.

11. J. A. Armstrong, S. E. Dann (2000) “Investigation of zeolite scales formed in the Bayer process” Microporous and Mesoporous Materials 41, 89-97.

12. G. Bánvögyi, A. Tóth, I. Tassy (1991) “In situ formation of sodium aluminium hydrosilicate from kaolinite” Light Metals 5-15.

13. T. Radomirovic, P. Smith, F. Jones (2012), “Using absorbance as a measure of turbidity in highly caustic solutions”, International Journal of Mineral Processing accepted, DOI: 10.1016/j.minpro.2012.11.005.

14. J. Temuujin, W. Rickard, M. Lee, A. van Riessen (2011), "Preparation and thermal properties of fire resistant metakaolin-based geopolymer-type coatings”, Journal of NonCrystalline Solids, 357(5) 1399-1404.

15. W. L. Connop (1996), “A new procedure for the determination of alumina, caustic and carbonate in Bayer liquors” Proceedings of the $3^{\text {rd }}$ Alumina Quality Workshop, Darwin Australia, 321-330.

16. K. C. Yang and R. Hogg (1979), "Estimation of Particle Size Distributions from Turbidimetric Measurements”, Analytical Chemistry, 51(6), 758-763.

17. W. Zhou (2008) “Microscopic study of crystal defects enriches our knowledge of materials chemistry” J. Mater. Chem., 18, 5321-5325. 
18. J. L. Lowe, R. D. Hart, P. Smith, A. L. Rohl, G. M. Parkinson (2005), “Understanding growth of DSP in the presence of inorganic ions”, Proceedings of the $7^{\text {th }}$ Alumina Quality Workshop, Perth, Australia, 168-173.

19. J. L. Lowe, A. L. Rohl, J. D. Gale, P. G. Smith, G. M. Parkinson (2006), “Incorporation of impurity anions into DSP: insights into structure and stability from computer modelling” Molecular Simulation, 32(1), 35 - 44.

20. M. Jamialahmadi and H. Müller-Steinhagen (1998) “Determining silica solubility in Bayer process liquor” J. Miner., Nov, 44-49.

21. R. G. Breuer, L. R. Barsotti, A. C. Kelly (1963), "Behavior of silica in sodium aluminate solutions” Extr. Metallurgy Aluminium, 1, 133-156.

22. S. Ostap (1985), "Control of silica in the Bayer process used for alumina production: Impurity control, Disposal” Proceedings of CIM Annual Hydrometallurgy Meeting, 15, 1428.

23. G. I. D. Roach, A. J. White (1988) “Dissolution kinetics of kaolin in caustic liquors” Light Metals, 41-47.

24. R. M. Barrer, J. F. Cole, H. Sticher (1968), “Chemistry of soil mineral. Part V. Low temperature hydrothermal transformation of kaolinite” J. Chem Soc. (A), 2475-2485.

25. J. W. Mullin (1961) In Crystallization, 3rd ed.; Butterworth-Heinemann: Oxford, Chap 5 Nucleation.

26. Accessed online from webmineral.com on Jan 20, 2012. 


\section{Figure Captions}

Figure 1. Turbidity of synthetic Bayer liquor versus time with different waterglass solution additions (shown as $\mathrm{g} / \mathrm{L} \mathrm{SiO}_{2}$ added) at $80{ }^{\circ} \mathrm{C}$

Figure 2. SEM images taken of the solids collected after 300 minutes from the turbidity runs shown in Figure 1. (a) $0.68 \mathrm{~g} / \mathrm{L}$ (b) $1.1 \mathrm{~g} / \mathrm{L}$ (c) $1.9 \mathrm{~g} / \mathrm{L}$ and (d) $2.2 \mathrm{~g} / \mathrm{L} \mathrm{SiO}_{2}$

Figure 3. Turbidity versus time plots for different $\mathrm{g} / \mathrm{L} \mathrm{SiO}_{2}$ additions of sodium metasilicate at (a) $80{ }^{\circ} \mathrm{C}$ and (b) $90{ }^{\circ} \mathrm{C}$

Figure 4. $\quad$ SEM images of the products formed at (a and c) 10 minutes and (b and d) 5 hours with (a and b) $2.3 \mathrm{~g} / \mathrm{L}$ and (c and d) $1.1 \mathrm{~g} / \mathrm{L} \mathrm{SiO}_{2}$ addition at $90{ }^{\circ} \mathrm{C}$

Figure 5. $\quad \mathrm{XRD}$ pattern of solids obtained with metasilicate addition after 10 minutes at $80^{\circ} \mathrm{C}\left(2.9 \mathrm{~g} / \mathrm{L} \mathrm{SiO}_{2}\right)$ and $90^{\circ} \mathrm{C}\left(2.3 \mathrm{~g} / \mathrm{L} \mathrm{SiO}_{2}\right)$

Figure 6. Kaolinite dissolution in synthetic Bayer liquor at $80^{\circ} \mathrm{C}$ and at (a) different FC levels but constant $\mathrm{A} / \mathrm{C}=0.4$ and (b) constant FC level (119 g NaOH) but different $\mathrm{A} / \mathrm{Cs}$

Figure 7. 'Dissolution' of kaolinite at $90{ }^{\circ} \mathrm{C}$ as monitored by the UV-Vis method

Figure 8. Absorbance results and SEM results combined to show simultaneous dissolution of kaolinite $\left(0.5 \mathrm{wt} \% 90^{\circ} \mathrm{C}\right)$ and nucleation of DSP

Figure 9. DLS results showing counts (particle number) versus time at different sonication power

Figure 10. Ex-situ tapping mode AFM images obtained of kaolinite in synthetic Bayer liquor after 120 minutes. (a) height image (b) phase image of same area. 


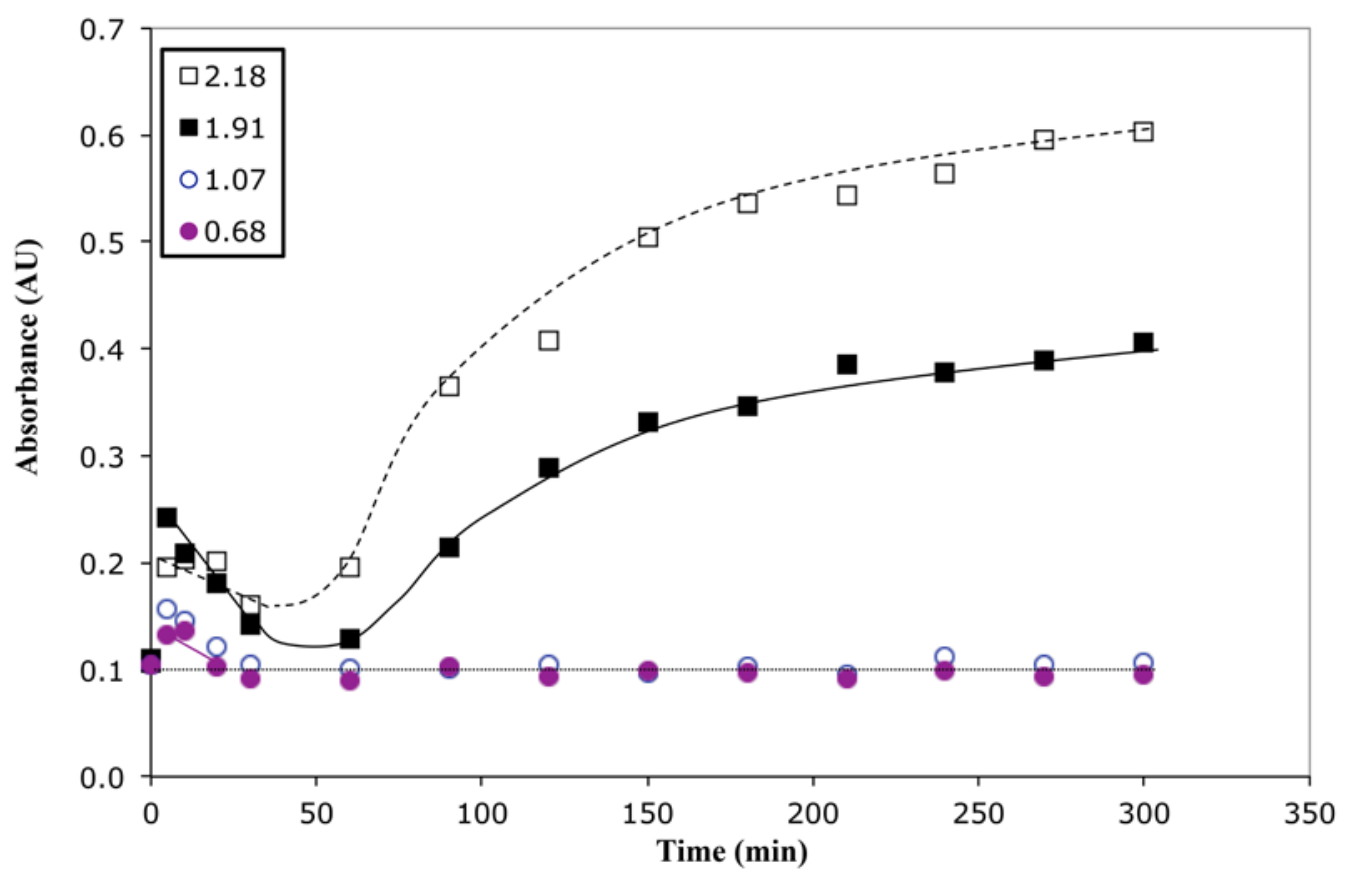

Figure 1. Turbidity of synthetic Bayer liquor versus time with different waterglass solution additions (shown as g/L SiO 2 added) at $80{ }^{\circ} \mathrm{C}$
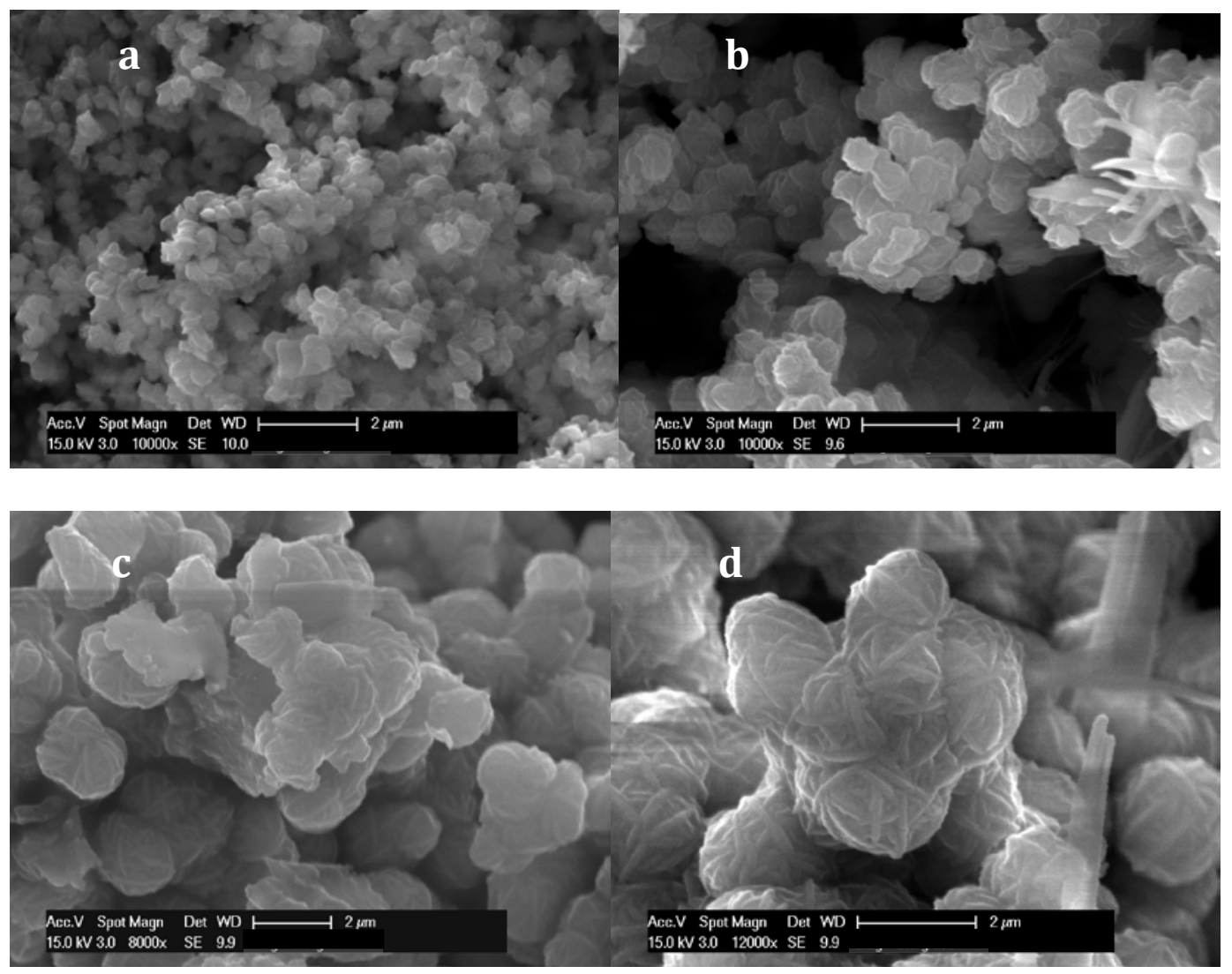

Figure 2. SEM images taken of the solids collected after 300 minutes from the turbidity runs shown in Figure 1. (a) $0.68 \mathrm{~g} / \mathrm{L}$ (b) $1.1 \mathrm{~g} / \mathrm{L}$ (c) $1.9 \mathrm{~g} / \mathrm{L}$ and (d) $2.2 \mathrm{~g} / \mathrm{L}$ $\mathrm{SiO}_{2}$ 


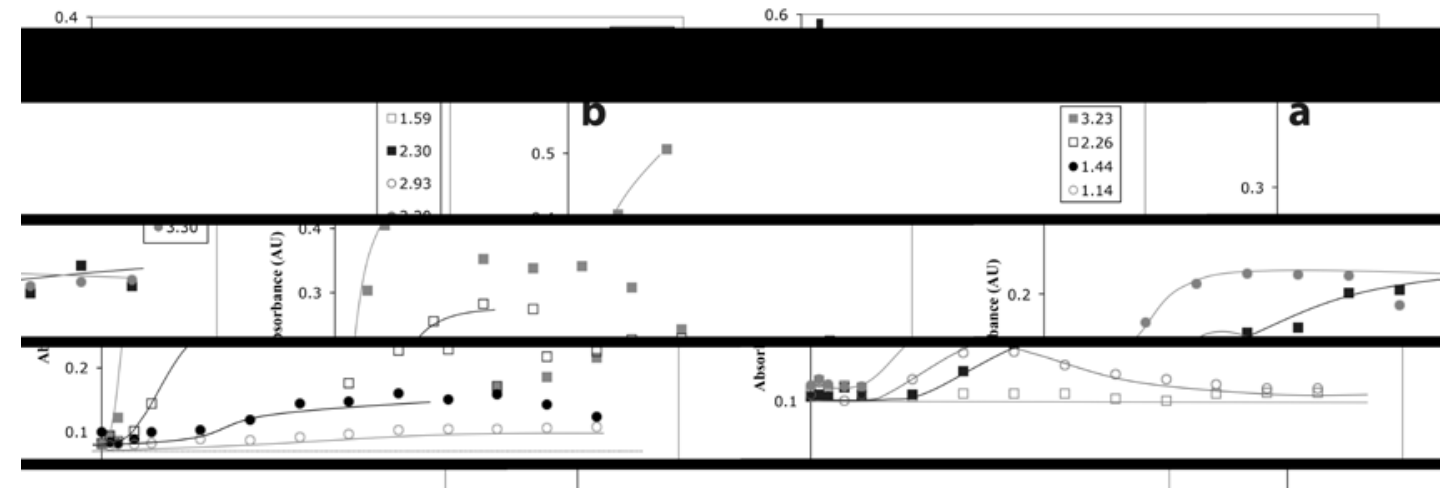

Figure 3. Turbidity versus time plots for different $\mathrm{g} / \mathrm{L} \mathrm{SiO}_{2}$ additions of sodium metasilicate at (a) $80{ }^{\circ} \mathrm{C}$ and (b) $90^{\circ} \mathrm{C}$
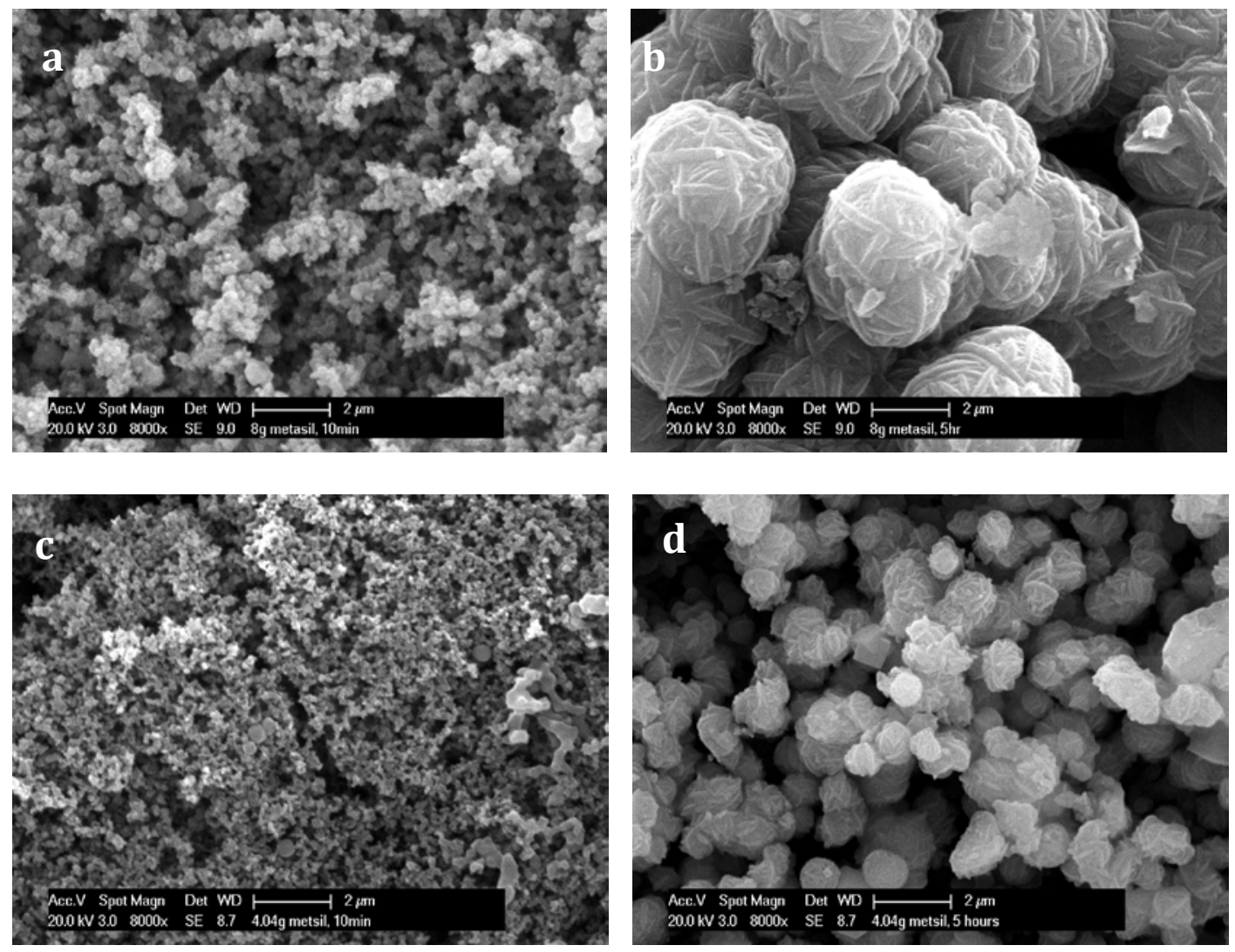

Figure 4. SEM images of the products formed at (a and c) 10 minutes and (b and d) 5 hours with (a and b) $2.3 \mathrm{~g} / \mathrm{L}$ and (c and d) $1.1 \mathrm{~g} / \mathrm{L} \mathrm{SiO}_{2}$ addition at $90{ }^{\circ} \mathrm{C}$ 


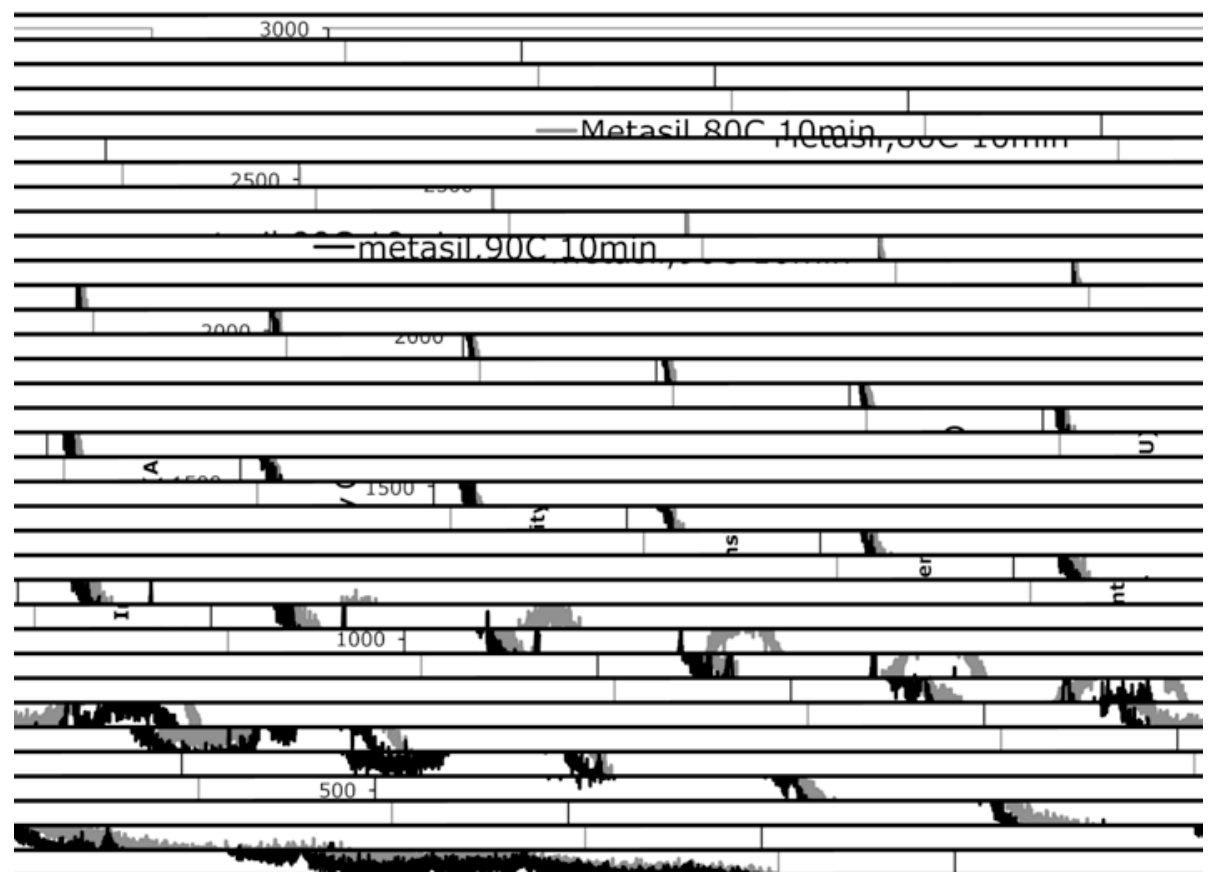

Figure 5. XRD pattern of solids obtained with metasilicate addition after 10 minutes at $80{ }^{\circ} \mathrm{C}\left(2.9 \mathrm{~g} / \mathrm{L} \mathrm{SiO}_{2}\right)$ and $90{ }^{\circ} \mathrm{C}\left(2.3 \mathrm{~g} / \mathrm{L} \mathrm{SiO}_{2}\right)$

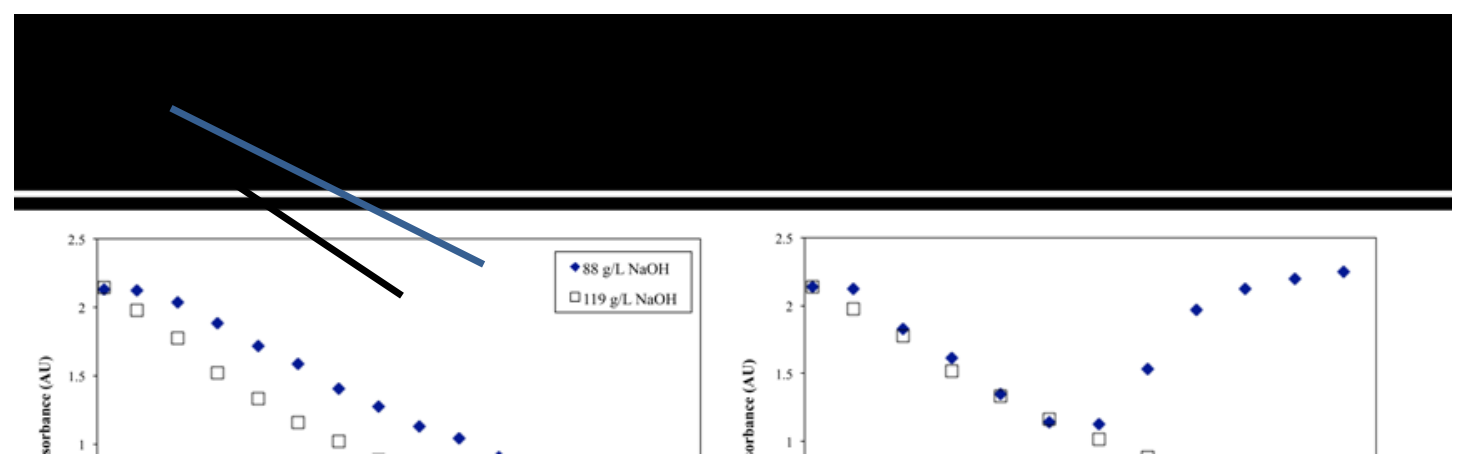

Figure 6. Kaolin dissolution in synthetic Bayer liquor at $80^{\circ} \mathrm{C}$ and at (a) different FC levels but constant $\mathrm{A} / \mathrm{C}=0.4$ and (b) constant $\mathrm{FC}$ level $(119 \mathrm{~g} \mathrm{NaOH})$ but different $\mathrm{A} / \mathrm{Cs}$

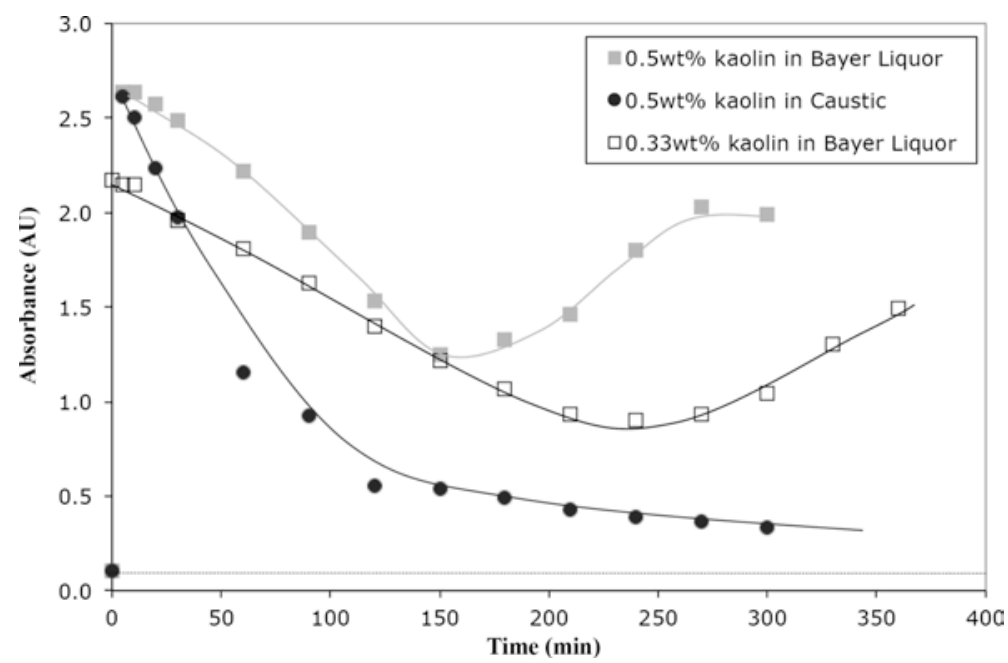

Figure 7. 'Dissolution' of kaolin at $90{ }^{\circ} \mathrm{C}$ as monitored by the UV-Vis method 


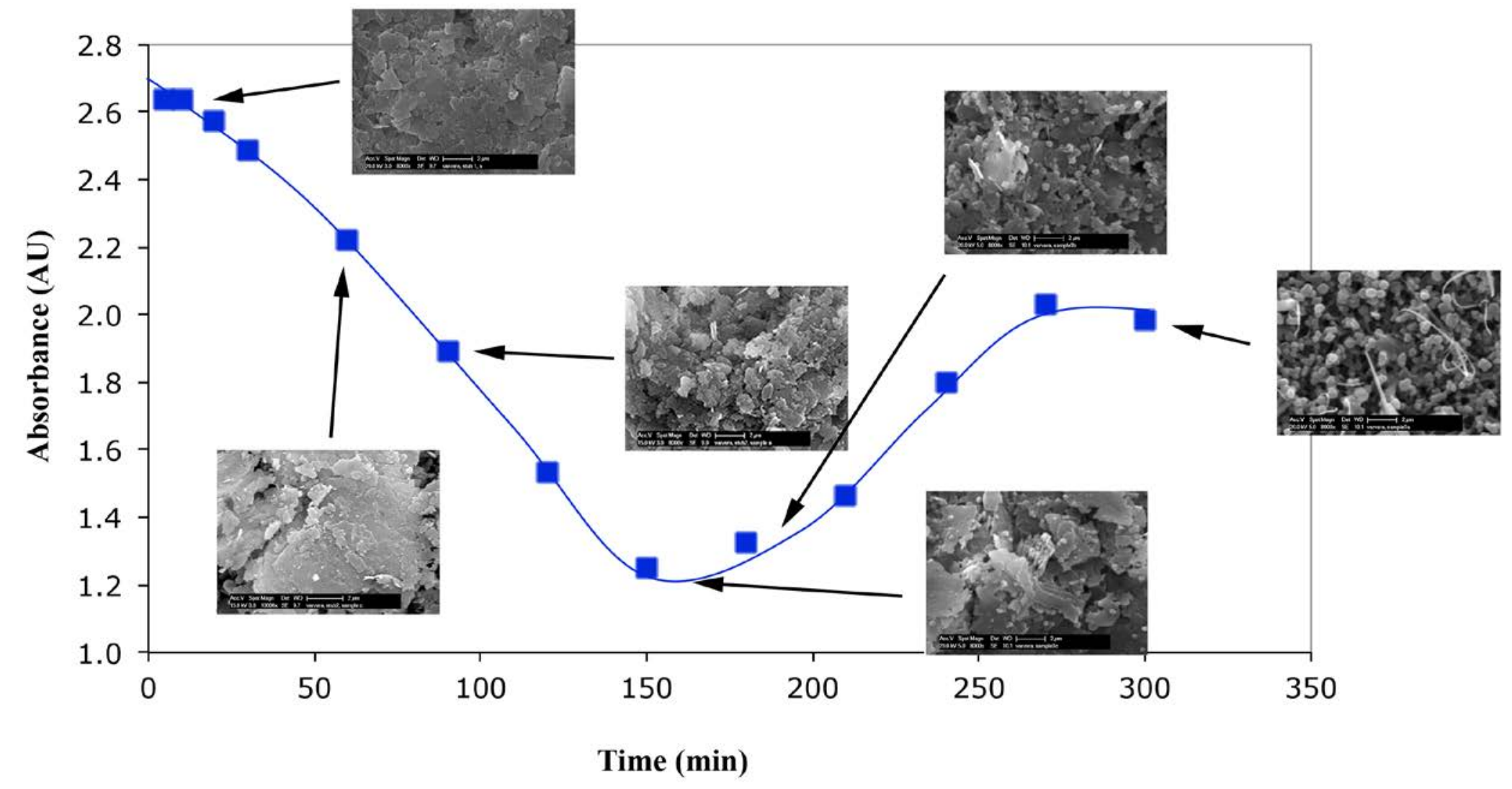

Figure 8. Absorbance results and SEM results combined to show simultaneous dissolution of kaolin $\left(0.5 \mathrm{wt} \% 90^{\circ} \mathrm{C}\right)$ and nucleation of DSP 


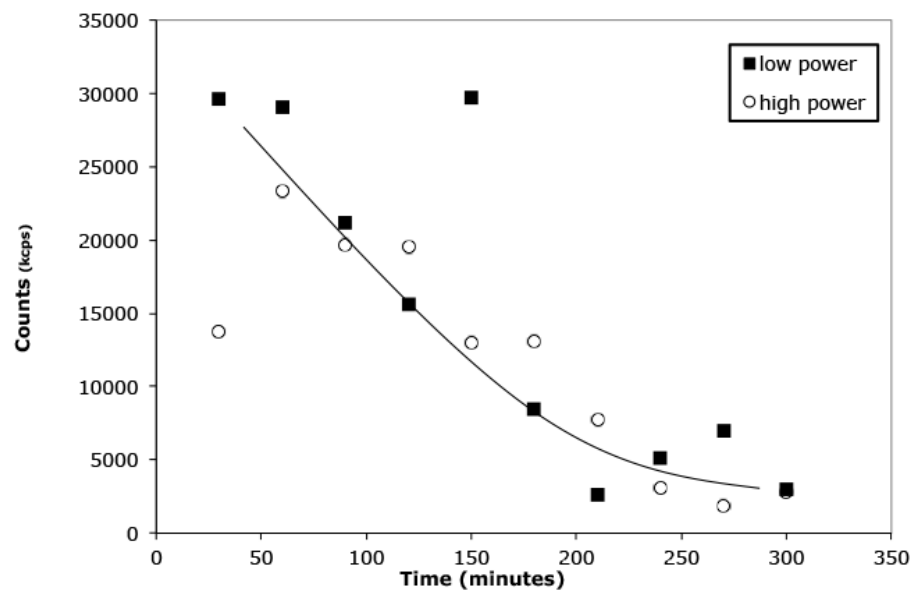

Figure 9. DLS results showing counts (particle number) versus time at different sonication power
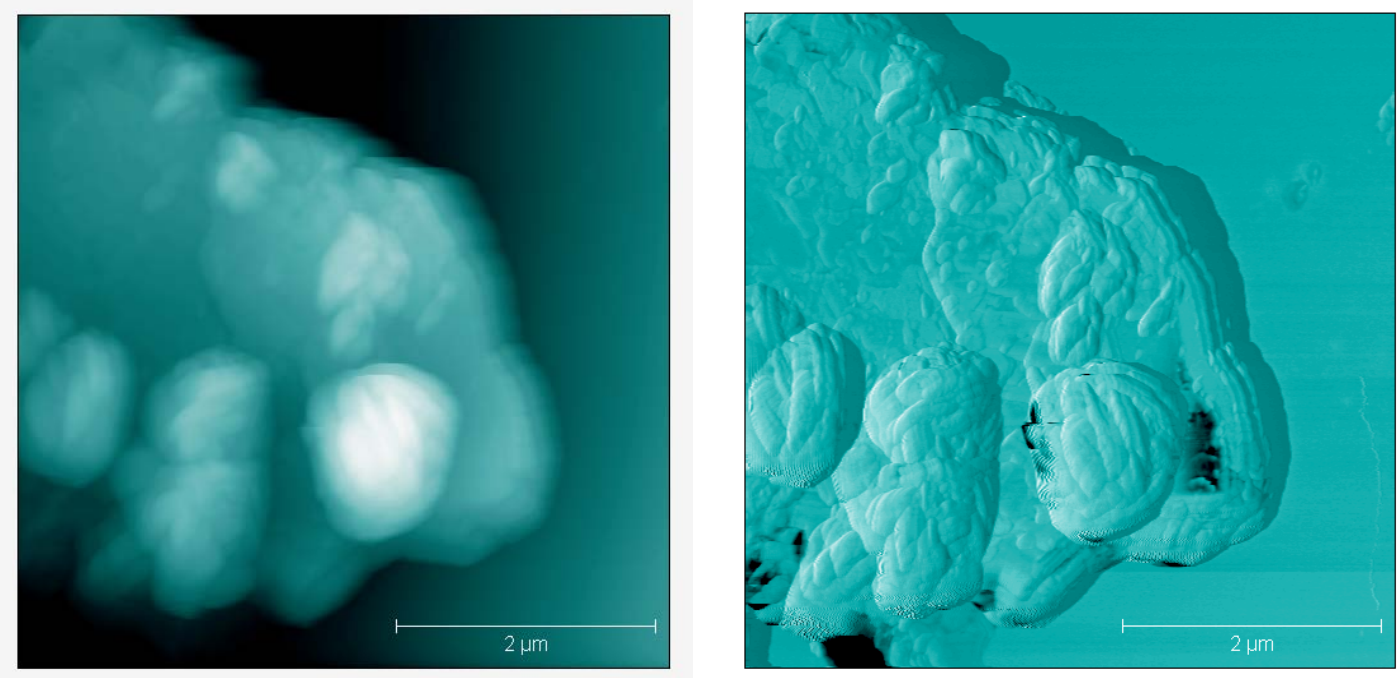

Figure 10. Ex-situ tapping mode AFM images obtained of kaolin in synthetic Bayer liquor after 120 minutes. (a) height image (b) phase image of same area. 
Supplementary figures

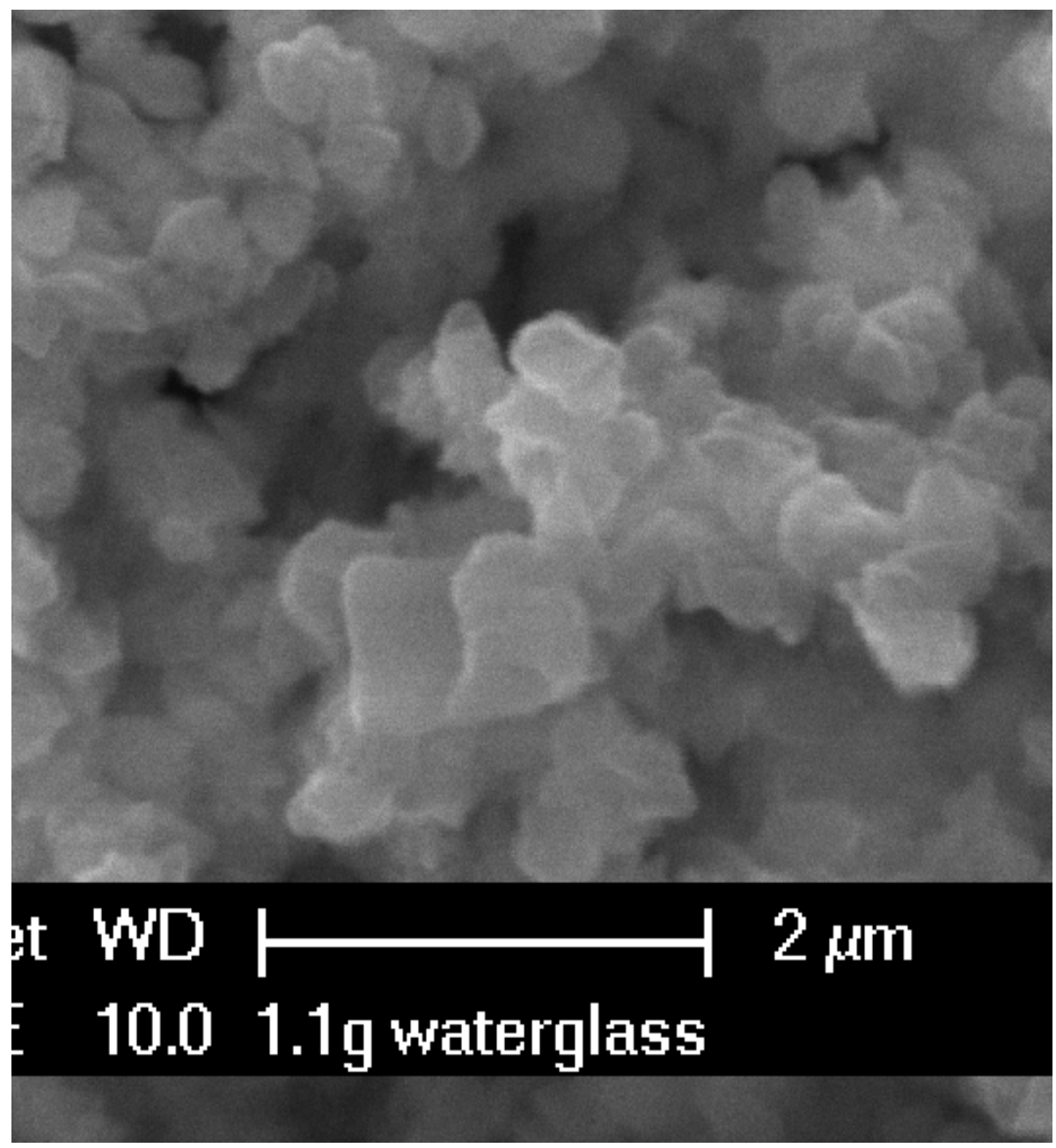

Figure S1. Magnification of figure 2a showing platelet morphology 


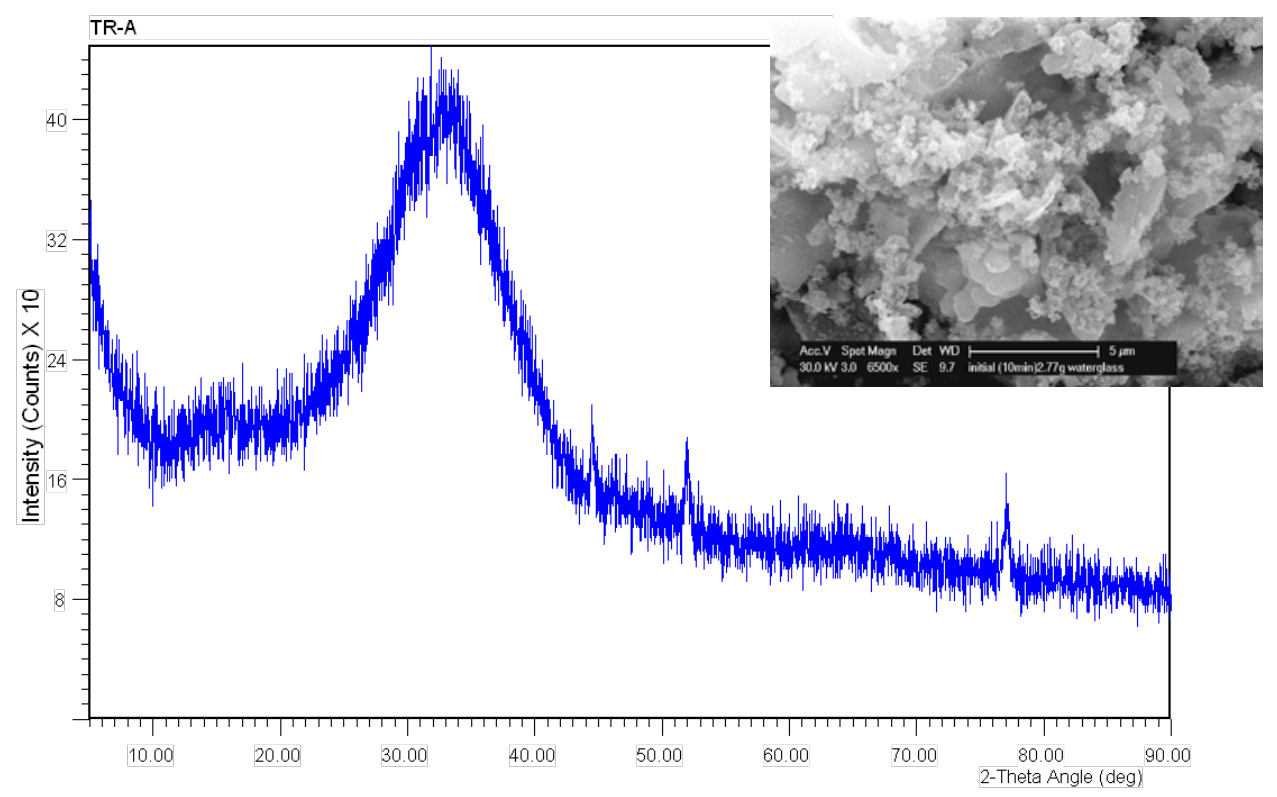

Figure S2. XRD pattern obtained from solids collected at 10 minutes when 2.2 $\mathrm{g} / \mathrm{L} \mathrm{SiO}_{2}$ was added to synthetic Bayer liquor and the resultant SEM image of those solids

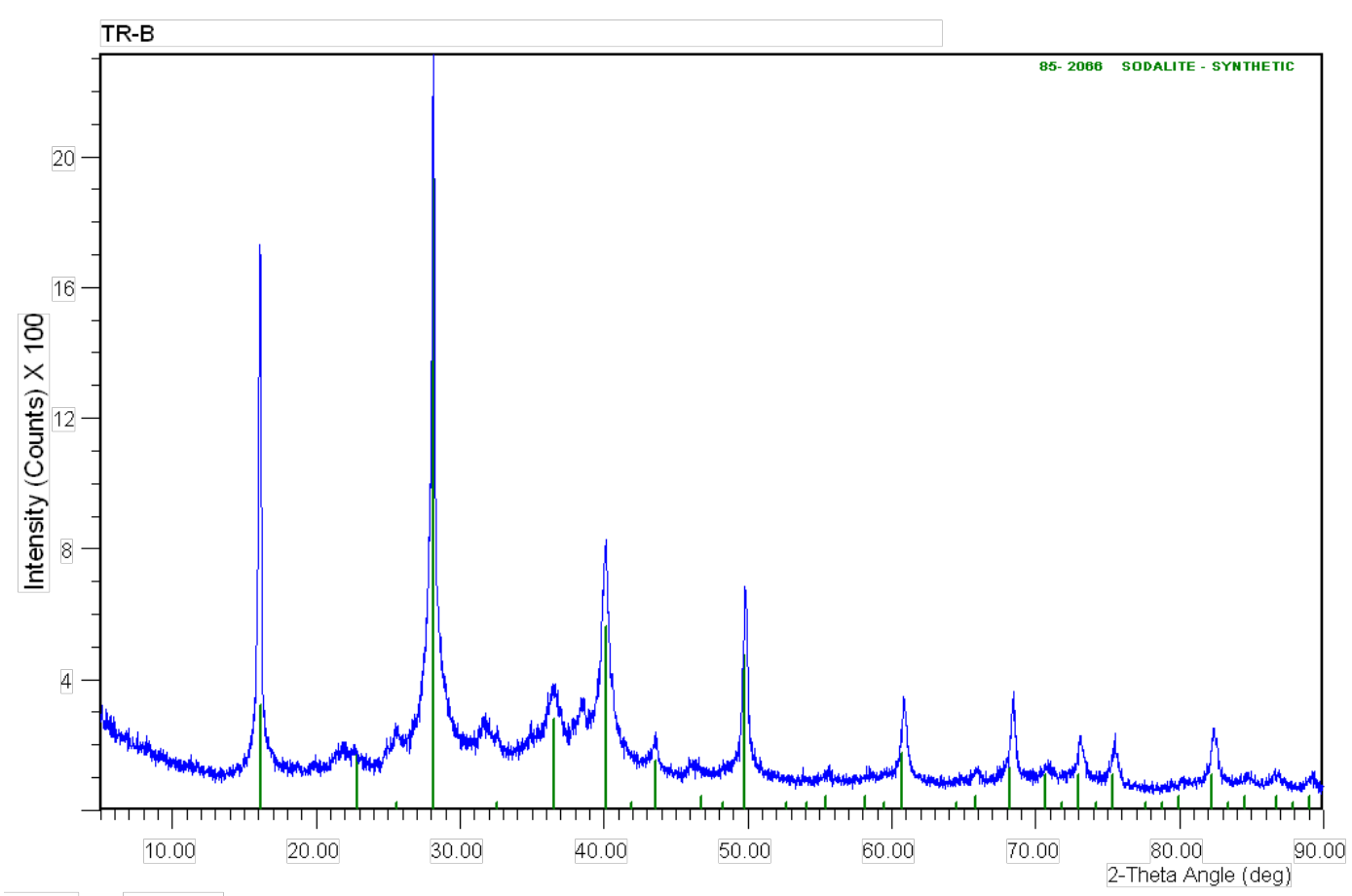

Figure S3. XRD pattern obtained from solids collected after 300 minutes when $2.2 \mathrm{~g} / \mathrm{L} \mathrm{SiO}_{2}$ waterglass solution was added to synthetic Bayer liquor 


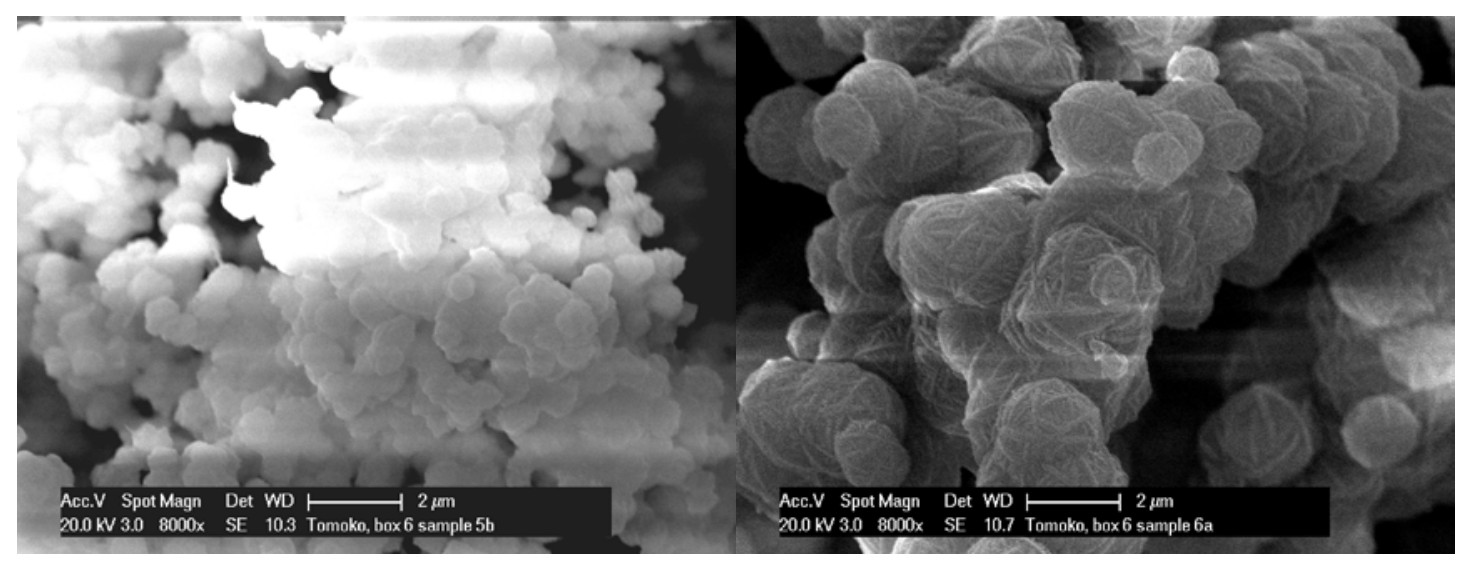

$1.50 \mathrm{~g} / \mathrm{L} \mathrm{SiO}_{2}$

$2.30 \mathrm{~g} / \mathrm{L} \mathrm{SiO}_{2}$

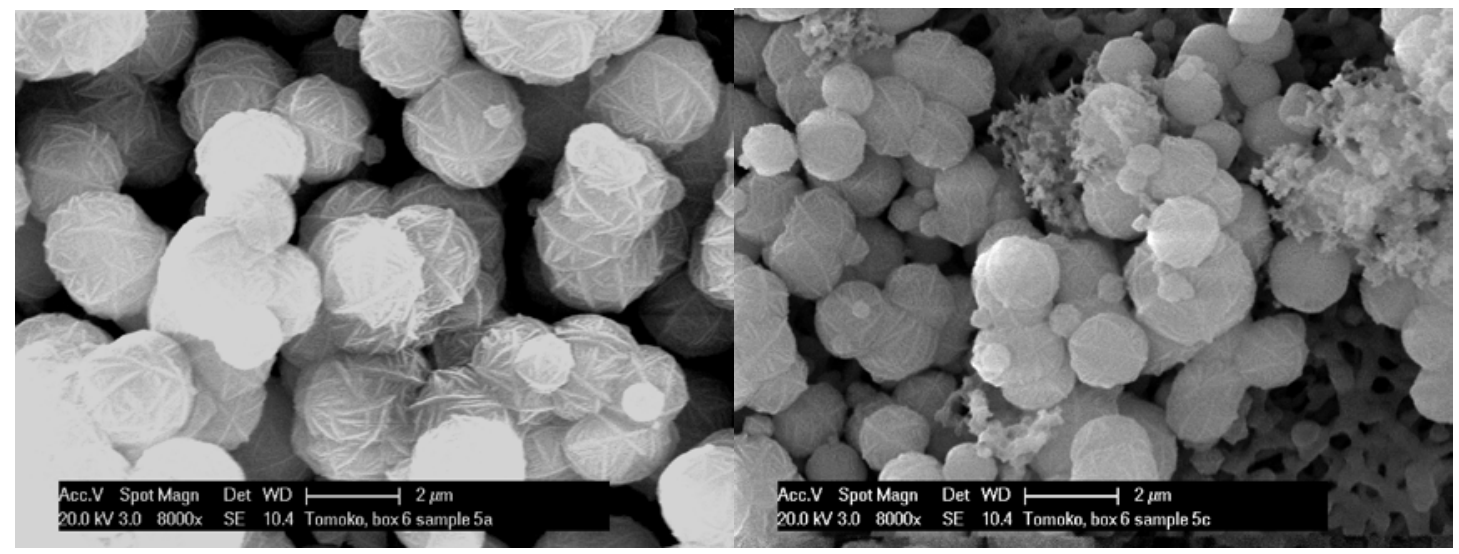

$2.93 \mathrm{~g} / \mathrm{L} \mathrm{SiO}_{2}$

$3.30 \mathrm{~g} / \mathrm{L} \mathrm{SiO}_{2}$

Figure S4. SEM images of the particles formed at $80^{\circ} \mathrm{C}$ and sodium metasilicate addition at the concentrations shown. 


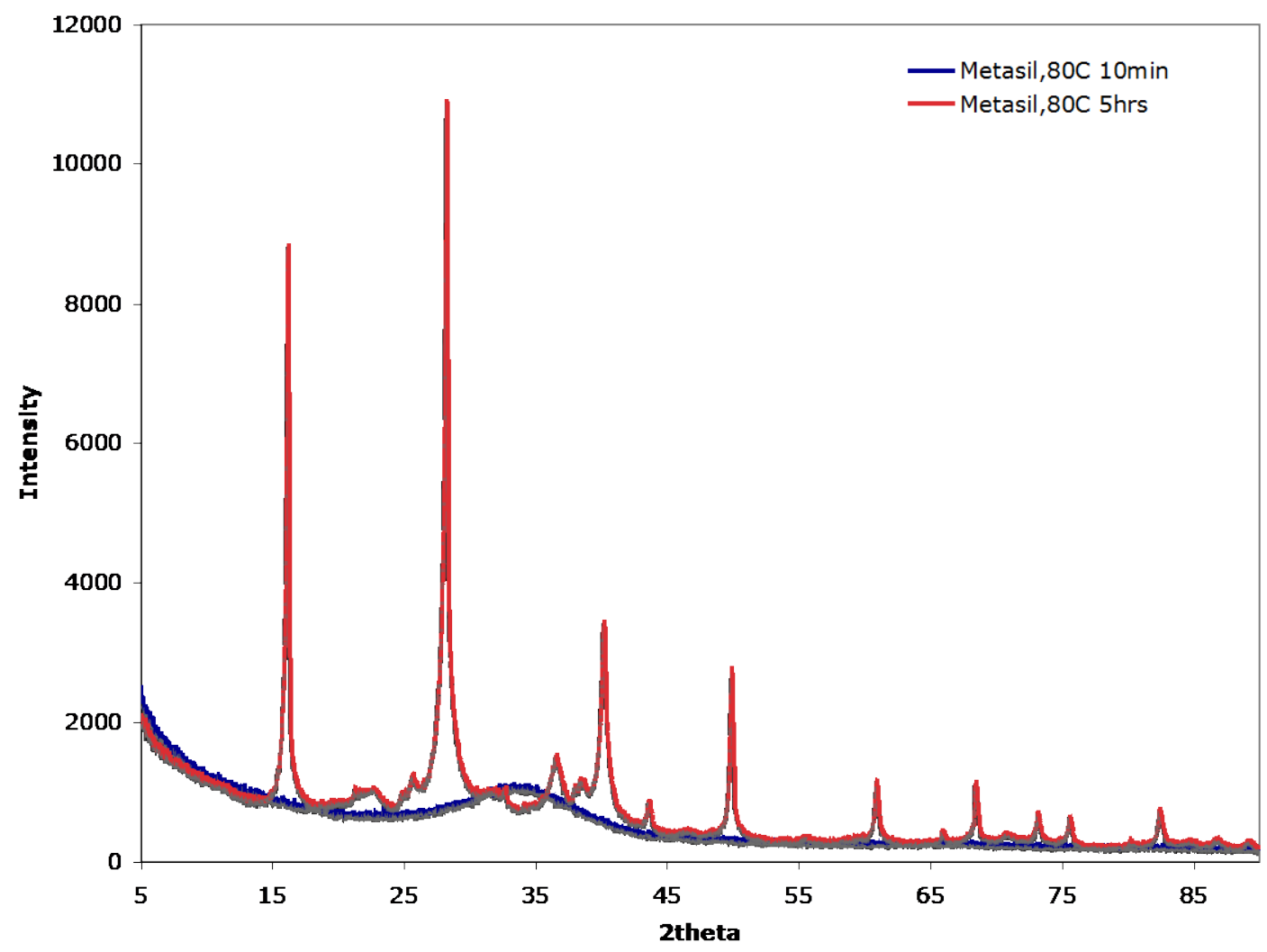

Figure S5. XRD pattern of solids formed on $2.9 \mathrm{~g} / \mathrm{L} \mathrm{SiO}_{2}$ addition of metasilicate solution to Bayer liquor at $80^{\circ} \mathrm{C}$.

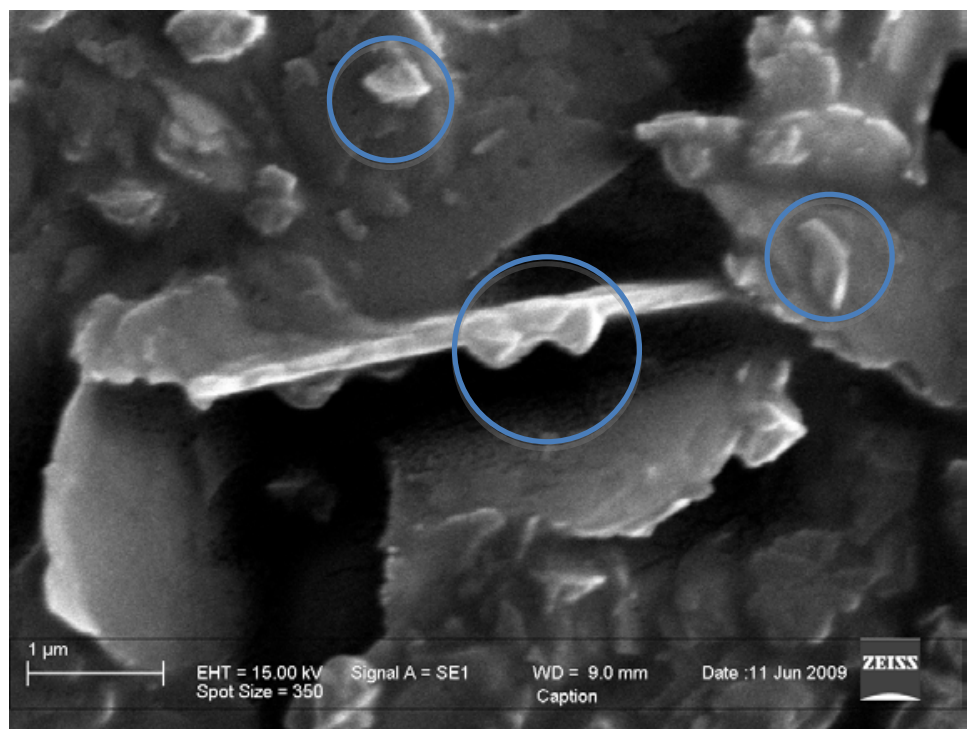

Figure S5. High magnification SEM image of the kaolin with DSP formed appears to show that the first heterogenous nuclei of DSP form perpendicularly to the kaolin (some shown in circles) 


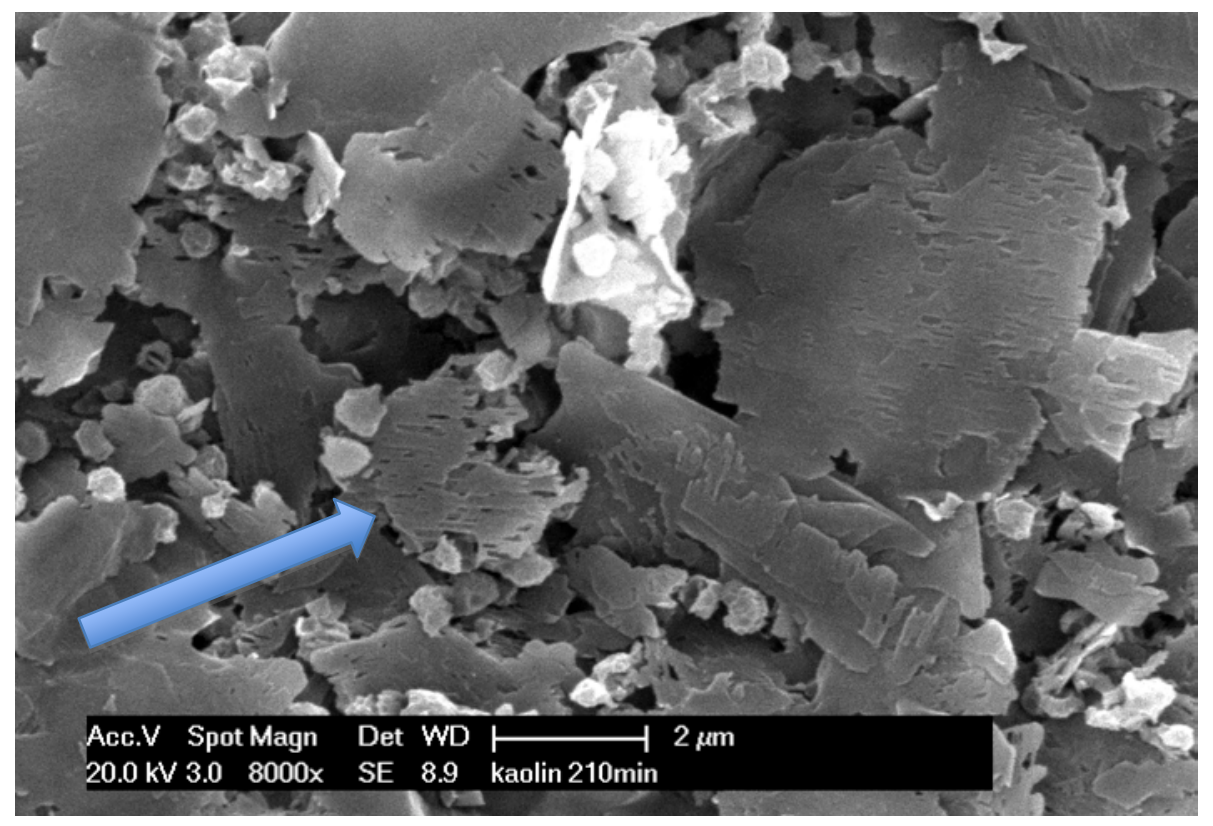

Figure S7. SEM image of kaolin dissolution at 210 minutes in synthetic Bayer liquor at $90{ }^{\circ} \mathrm{C}$ (showing obvious signs of kaolin dissolution as pointed out by the arrow) 